\title{
La alteridad en María Zambrano
}

\author{
Greta Rivara Kamaji
}

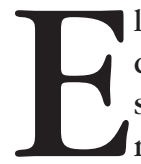

1 presente texto pretende explicar sucintamente la noción de alteridad en la filosofía de María Zambrano. La autora española construye su reflexión en torno al tema de la alteridad a través de una catego-

ría central en su pensamiento: la piedad. Zambrano reposiciona el sentido ordinario de tal palabra, de manera que es a través de este reposicionamiento que construye su noción de alteridad; busca hacer de esta noción la condición de posibilidad para construir una racionalidad dialógica desde un terreno distinto al de algunas teorías contemporáneas sobre el diálogo, la alteridad y las distintas posibilidades de una racionalidad que esté pensada en consecuencia con dicha noción. Trataremos de vislumbrar en qué sentido la originalidad del planteamiento zambraniano aporta elementos significativos a las discusiones contemporáneas, ya que su idea de alteridad y la posible racionalidad dialógica que se deriva de ella, incluye una posición intermedia entre posiciones aparentemente antagónicas que suelen nombrarse como la tensión entre normativismo y relativismo o universalismo y contextualismo. Considero que la aportación zambraniana al respecto es sugerente y útil para pensar problemas de primer orden, por ejemplo, los temas relacionados con la diversidad de tradiciones, el problema de la singularidad y especificidad de las mismas, y si es que ello excluye o no cualquier posibilidad de fijar parámetros universales de interpretación.

En El hombre y lo divino, Zambrano hace una especie de microhistoria sobre la noción de piedad y la vincula con la de alteridad. Son cuatro los momentos significativos por los que transita para analizar la categoría de piedad, de los cuales se nutre para construir su propia idea de alteridad y para fijar eventualmente los cimientos de una racionalidad dialógica: primero, la religiosidad griega; segundo, la tragedia griega; tercero, la emergencia de la filosofía y, finalmente, el estoicismo latino. Estos momentos, o la reflexión sobre ellos, están engarzados por el horizonte desde el cual la filósofa va a construir su 
idea de piedad, es decir, su crítica a la tradición racionalista. A partir de aquella microhistoria construye su propuesta y define a la piedad como un saber: un saber tratar adecuadamente con lo otro. Un saber que, según Zambrano, estuvo ausente en los extremos del racionalismo occidental. De este modo se propone construir una racionalidad que llama piadosa, es decir, una racionalidad que sepa no sólo tratar con lo otro, sino hacerlo adecuadamente. Se trata para la filósofa española de una racionalidad dialógica cuyas características centrales son, por un lado, no renunciar a la universalidad y, por el otro, no renunciar tampoco a la singularidad que toda alteridad expone.

La esencia del racionalismo radica en que éste, a lo largo de su historia, ha excluido, negado, olvidado y desconocido ámbitos de la vida, del pensamiento, por considerarlos no sólo imposibles de racionalizar, sino ajenos a la razón misma y, por tanto, ajenos al reino del conocimiento verdadero. Todo aquello que la razón, en su versión racionalista, exclusivamente discursiva y teorética, consideró extrarracional o bien irracional, quedó desplazado y condenado a la sombra, al oscuro recinto donde habita lo incognoscible, lo soterrado por la claridad del intelecto y la conciencia racionalista. Pues bien, la filosofía de Zambrano se dio a la tarea -siguiendo a pensadores como Nietzsche- de pensar esas sombras, de desenterrar lo enterrado por la razón. Descender a esos ínferos, a esos abismos del ser, constituye el móvil fundamental de nuestra autora. Devolver la razón, el conocimiento y la verdad a todo aquello "humillado" por el racionalismo, a todo aquello que nunca consideró digno de intelección, es "lo otro" del racionalismo que Zambrano pretende pensar. ${ }^{1}$

La filosofía racionalista, según nuestra autora, no sólo delimitó y redujo el mundo a la medida de sus categorías, sino que también delimitó y validó los saberes que pueden conocer racionalmente el mundo, sacando del reino del conocimiento aquellos saberes que no consideró, desde su propio tribunal, dignos de otorgar conocimiento. Tal es el caso de la poesía, a la que la filosofía racionalista le dejaría como espacio propio ese reino de sombras que ella misma había generado en su excluyente tribunal. De este modo, el racionalismo construyó "lo otro" de la razón, que desde el punto de vista del conocimiento

${ }^{1}$ Del sentimiento de diferencia, de extrañeza y de fragilidad provienen en el hombre sus acciones, las cuales van desde el conjuro al exorcismo de la realidad, que en un momento debió parecerle lo más hostil e intratable, pues al no tener nombre ni contenido lo desborda, llegando hasta la invención de los dioses como posibilidad de tratar con ella, de hacerla un espacio nominable y habitable. Este tema lo desarrolla Zambrano en su libro El hombre y lo divino, en el cual explica que la aparición de los dioses conlleva una función fundamental, hacerle al hombre accesible la realidad, la posibilidad de tratarla y comenzar a nombrarla y a organizarla, de este modo, los dioses representan una especie de vínculo con la realidad, un vínculo que aplaca el terror de no poder pisar una realidad que parece extraña, que no se puede nombrar aún. $C f$. María Zambrano, "Del nacimiento de los dioses", en El hombre y lo divino. México, FCE, 1993. 
identificó con lo inferior, con lo ininteligible, con lo no susceptible de arrojar verdades. Esto "otro" de la razón, su sombra, su abismo, es también su exclusión, su diferencia, su desconocimiento; es la negación del racionalismo a brindar ser al no-ser, realidad a lo múltiple, discontinuo, ambiguo y plural. Es la exclusión de la alteridad por inapresable frente a la unidad y a la homogeneidad que siempre ha buscado la razón, unidad que se ha constituido como condición indispensable del conocimiento.

En consecuencia, Zambrano afirma que el racionalismo, además de convertir extensas zonas de la vida en "lo otro", tampoco ha sabido tratar con eso otro; más aún, lo volvió indigno, lo excluyó, lo nombró como irracional y devaluó todo saber que pretendiese reivindicar eso otro que, paradójicamente, es también la vida: el no-ser, el abismo, el cuerpo, los instintos, la irracionalidad, la ambigüedad, la contradicción, los sentimientos, las entrañas, la luz y la oscuridad, lo efímero y lo finito, lo heterogéneo y lo discontinuo. Podríamos contar la historia de la filosofía desde sus exclusiones; por ejemplo, el exilio que hizo de la poesía y en general del arte del reino de la verdad y del conocimiento. ${ }^{2}$ El racionalismo, al sustituir la vida por el concepto, la redujo a aquello que consideró racional; lo demás quedaba oculto, latiendo en los ínferos, desconocido, humillado, mas nunca borrado o desaparecido.

Es en este contexto en el que Zambrano construye la idea de "piedad", a la que define como "un saber tratar adecuadamente con lo otro", 3 a partir de una reflexión en torno al Eutifrón de Platón. No vamos a ahondar aquí en la manera en cómo llegó a su definición, partiremos de ella: piedad quiere decir un saber tratar con lo otro. La piedad funciona en su pensamiento como una metáfora para nombrar la exclusión de todo lo que el racionalismo constituyó como otredad. Precisamente esta idea de piedad como un saber tratar con lo otro es la que opera en la crítica que Zambrano hace al racionalismo en la medida en que éste no supo o no pudo tratar con lo otro. De este modo, la idea de piedad no sólo es importante desde la perspectiva de la crítica zambraniana, sino justamente desde sus propuestas filosóficas. Dichas propuestas pueden resumirse en construir una racionalidad distinta de la racionalista con el fin de poder reconocer, como realidad y conocimiento, todo aquello que para el racionalismo simplemente quedaba fuera del concepto, fuera de la intelección

${ }^{2}$ Si bien esto ya había sido denunciado por Nietzsche, Zambrano intenta seguir transitando por ese camino.

${ }^{3}$ Es importante notar que nuestra autora reposiciona tal idea y la descarga de su significado habitual, es decir, cristiano. La piedad, afirma Zambrano, no es la caridad, forma descubierta por el cristianismo; no es ni siquiera la compasión. "La primera definición propuesta es que piedad es la virtud que hace tratar debidamente a los dioses para acabar en la conclusión de que es lo que trata de lo injusto y lo justo" (M. Zambrano, op. cit., p. 202). 
de la conciencia, fuera del mundo reducido a objeto de conocimiento, fuera de la conciencia de un sujeto a quien se redujo el ser del hombre dentro del racionalismo.

La historia del pensamiento - anota nuestra autora- encubre procesos que tienen lugar o han tenido lugar en lo más profundo de la conciencia, lugares donde la misma conciencia encubre las creencias, pero más que eso, más profundo que eso, las formas íntimas de la vida humana; esto es, aquello que define al ser humano "no ya frente a lo humano, sino a toda la realidad que le rodea", ${ }_{4}^{4}$ puesto que la realidad no es sólo aquella que el pensamiento puede atrapar, definir y captar, sino algo otro indefinible, algo que queda al margen de las captaciones racionales y que, sin embargo, rodea a la conciencia, y al hacerlo la destaca "como isla de luz en medio de las tinieblas".

El racionalismo extremo, como ya lo había señalado Ortega y Gasset en "Ni vitalismo ni racionalismo", ${ }^{6}$ llega a sus últimas consecuencias cuando asume que la razón accede, capta y define todo, absolutamente todo. El racionalismo moderno, afirma Zambrano, pierde de vista la unidad última del universo, en quien ve sólo la uniformidad que la razón ordena y gracias a la cual puede llegar a tener sentido, y no sólo sentido, sino orden y ser.

Y es que a partir del pensamiento cartesiano la conciencia ganó en claridad y nitidez y, al ensancharse, se apoderó del hombre todo. Y lo que iba quedándose fuera no eran cosas, sino nada menos que la realidad, la realidad oscura y múltiple. Al reducirse el conocimiento a la razón solamente, se redujo también eso tan sagrado que es el contacto inicial del hombre con la realidad a un modo único: el de la conciencia. Quedaba la conciencia en su claridad lunar aislada hasta el propio cuerpo, donde por no se sabe qué azarosa contingencia venía a estar insertada. $^{7}$

De este modo, el hombre, al engrandecerse como centro explicativo del universo, también se reducía a ser únicamente el sustento del conocimiento racional. Esta magnificación y esta reducción provocaron a la par la reducción de la realidad, pues ésta tenía que adaptarse, estrecharse a la medida del conocimiento. Así, señala Zambrano, en la misma proporción en la que el sujeto se magnificaba como centro del universo, la realidad quedaba reducida y empequeñecida a su paso. Todo lo que no podía ser captado racionalmente

${ }^{4}$ Ibid., p. 191.

${ }^{5}$ Idem.

${ }^{6}$ Vid. José Ortega y Gasset, "Ni vitalismo ni racionalismo", en Obras completas, vol. III. Madrid, Revista de Occidente, 1924.

${ }^{7}$ M. Zambrano, op. cit., pp. 191-192. 
sería sacrificado al desconocimiento, al no reconocimiento. Así, llegó a pensar el sujeto que sólo "es" lo que él racionaliza, ordena, mide y cuantifica. Pero no sólo la realidad se acortaba, sino el ser del hombre, ahora solamente definido por su razón.

La vida es movimiento perpetuo, vivir es estar en movimiento, mas el movimiento genera horror, horror a la multiplicidad que desmiente cada acto del pensamiento. Por eso, el pensamiento ha buscado descubrir presencias puras, transparentes, anular el tiempo para generar la tranquilizadora coincidencia entre su mirada y el objeto mirado: una seguridad frente al horror de todo lo deveniente y efímero. Éste parece ser el signo de toda filosofía racionalista, modificar al mundo y nombrar lo innombrable, dar lugar a quien no lo tiene: el hombre. Situar a partir de él el lugar de todo aquello que no es él. Puede entonces esta clase de saber conocer todo y por tanto controlar, aunque sea por momentos, el inexorable transcurrir de las cosas.

A pesar de ello, del pensar, del pensar de la unidad, la vida humana transcurre diversa y en diversas realidades; esto a pesar de que el pensar "racional" que capta lo que es y cómo es, deje fuera lo que es a medias, lo que es y no es, lo que no obedece a los principios lógicos. De este modo, podríamos decir que para aquel pensamiento no todo lo que hay es ser. Hay aquello que hay y sin embargo no es. No es, pero afecta nuestra vida, constituye nuestra realidad y, sin embargo, ante nuestra mirada no tiene unidad.

Este reino - el de la realidad sin ser- es el de la cualidad simple, y aun el término cualidad parece excesivamente racionalista para sugerir esa condición de lo que no podemos nombrar de ninguna manera. La cualidad es siempre un salto; toda cualidad parece estar rodeada de un abismo, emerge sorprendiéndonos con su misterio [...] La razón, naturalmente, ha pretendido siempre reducir la cualidad a lo mensurable, a lo continuo. ${ }^{8}$

Así, el hombre postcartesiano y posthegeliano es un creyente cuya fe radica en ver que la razón es el único medio para relacionarse con la realidad, anota Zambrano. Frente a esta razón discursiva, el hombre se ve rodeado de cualidades, de "semi-seres" irreductibles a razones. El hombre, engendro del racionalismo, "se ve asechado por cosas que no lo son y que aparecen inconexas; en suma, por ese mundo de lo monstruoso que el arte lograba de algún modo apresar". 9 Sin embargo, el "saber absoluto" absorbe e integra a la poesía, al arte, que la razón disolvía en sus mismos procesos. Y el hombre

${ }^{8}$ Ibid., p. 196.

${ }^{9}$ Idem. 
concreto, ¿logra vivir en este saber?, se pregunta Zambrano. ¿No queda acaso perdido, naufragando en aquella isla que parecía salvarle?

Por más que el racionalismo intentó captar cognoscitivamente la realidad, al hacerlo desconoció lo que no se reducía a su sistema, y el desconocimiento no hizo desaparecer todo aquel oscuro ámbito para la razón, de modo que seguía latiendo y palpitando, enfrentando al hombre a una realidad que ya le parecía extraña, abismática y frente a la cual quedaba nuevamente desarmado "pues hay algo en la vida humana insobornable ante cualquier ensueño de la razón: ese fondo último del humano vivir que se llaman las entrañas y que son la sede del padecer". ${ }^{10}$ A esto sólo se le puede ocultar pasajeramente, porque la vida humana es entraña, padecimiento, avidez, hambre, esperanza y mendicidad. El hombre es el ser que padece sin tregua su propio ser y no es posible reducir esto a la razón.

El hombre "siente" la multiplicidad, la contradicción, la finitud, la discordia, la discontinuidad, y a pesar de ello pretende acotar la realidad a lo continuo e idéntico, pero "sentir lo que no se dice, es estar condenado al silencio". ${ }^{11}$ Zambrano se pregunta si la razón puede ser la voz de aquello mismo que ha condenado silenciándolo. Lo otro de la razón que ha quedado humillado y sin voz en el reino de lo no cognoscible tendría que hablar un día, de algún modo, aun desde la humillación. ¿Trataría la lúcida conciencia con aquello que había convertido en "otro", en sombra, en silencio, en no-ser (y que sin embargo es vida)? "La vida humana, apetencia inextinguible de unidad, está rodeada de alteridad, lindando con 'lo otro'". ${ }^{12}$ Por ello eso "otro" irremediablemente nos interpela, nos interroga aun cuando nos neguemos a prestarle oídos, a escuchar su lamento, a sentir sus gemidos. Sin embargo, en su paso, la huella dejada por el racionalismo se traduce entonces en un no saber tratar adecuadamente con todo aquello que había convertido en su otro, en la máxima alteridad cuyo ser no es posible elevar a la dignidad de la razón. En resumen, Zambrano considera que no hay piedad en el racionalismo.

Se trata entonces de exigirle a la razón saber tratar con lo otro para construir una racionalidad dialógica, aquella que al reconocer sus límites y su finitud pueda abrir sus horizontes más allá de cualquier absorción de la alteridad en sus propios horizontes en un estéril monólogo autorreflejante. No se trata solamente de una racionalidad teorética que atienda a lo no atendido por la razón racionalista, se trata de una racionalidad social, política, capaz de construir a su vez una idea de persona. En Zambrano, este proyecto nunca está desligado de la vida de la persona, vida que es histórica, social y política. Ser persona es

\footnotetext{
${ }^{10}$ Ibid., p. 197.

${ }^{11}$ Idem.

${ }^{12}$ Ibid., p. 198.
} 
lo indispensable para toda racionalidad dialógica, y esto implica el saber tratar adecuadamente con lo otro. Ésta sería su tesis universalista, sin embargo, esta tesis no se entiende ni se sostiene sin una buena dosis de contextualismo: lo otro es singularidad y diferencia. Saber tratar con lo otro implica asumir las realidades diversas y singulares justamente en su particularidad, donde reside la auténtica universalidad.

El trato adecuado con lo otro sería lo universal de una racionalidad piadosa, pero es universal sólo en la medida en que asume el contexto en que cada universalidad puede darse, asume que lo que hay son contextos y diversidades que no pueden reducirse a ningún universalismo abstracto, esquemático y unitario que borre en sus conceptos fijos toda diferencia, todo movimiento, todo cambio. La vida de las diferencias es la vida de la persona, pero su vida en tanto que comparte su ser persona de manera universal. Trato adecuado con lo otro significa comprender antes que nada, comprender y ensanchar los horizontes de comprensión. Significa comprender al otro en su ser y no desde la propia individualidad de quien comprende, ya que esto cierra y limita el horizonte de comprensión de toda singularidad.

Entonces, saber tratar adecuadamente con lo otro significa no identificar la alteridad con la inferioridad, no absorber la alteridad del otro al propio horizonte, impidiendo con ello que el otro sea y se despliegue precisamente en su alteridad. Significa no absorber las alteridades en un todo homologador. Significa que el reconocimiento de la alteridad tampoco puede ser absolutizado para justificar el desconocimiento y la indiferencia o bien el control, el dominio y la opresión. Trato adecuado con lo otro significa, para Zambrano, que lo otro no lo es respecto a algo o alguien que se proclame como la identidad o el parámetro respecto del cual lo diferente a él sería lo otro y desde ahí sería medido. 